\title{
Erratum to: Iterative information update and stability of strategies
}

\author{
Takuya Masuzawa · Koji Hasebe
}

Received: 9 November 2010 / Accepted: 9 November 2010 / Published online: 18 January 2011

(C) Springer Science+Business Media B.V. 2011

\section{Erratum to: Synthese \\ DOI 10.1007/s11229-010-9835-y}

During the production of the article, some errors are overlooked.

In many places, the author's name of reference "Rational dynamics and epistemic logic in games" should be spelled "van Benthem", instead of "Van Benthem" if it is not the first word of a sentence.

Page 7 line 7 should read:

1. $W=\{U: U$ is a $S(\varphi)$-maximal consistent set. $\}$,

Page 14 line 7 should read:

Lemma 11 (Idempotency Lemma) Assuming that $q^{*} \in \mathcal{R}, \ldots$ (i.e., " $R$ " should be " $\mathcal{R}$ ").

Page 14 line 10 should read:

$\vdash E \Rightarrow\langle E\rangle \neg K_{i} q^{*}$ for all $i \in N$.

Page 14 line 20 should read:

Theorem 12 Let $q^{*} \in \mathcal{R} \ldots$

The online version of the original article can be found under doi:10.1007/s11229-010-9835-y.

T. Masuzawa

Faculty of Economics, Osaka University of Economics, 2-2-8 Osumi,

Higashiyodogawa-ku, Osaka 533-8533, Japan

e-mail: masuzawa@osaka-ue.ac.jp

K. Hasebe $(\varangle)$

Graduate School of Systems and Information Engineering, University of Tsukuba,

1-1-1 Tennoudai, Tsukuba 305-8573, Japan

e-mail: hasebe@iit.tsukuba.ac.jp 